\title{
Analysis and design of a compact ultra-wideband antenna with WLAN and X-band satellite notch
}

\author{
Mohssine El Ouahabi ${ }^{1}$, Aziz Dkiouak ${ }^{2}$, Alia Zakriti ${ }^{3}$, Mohamed Essaaidi $^{4}$, Hanae Elftouh $^{5}$ \\ ${ }^{1,2,3}$ Department of Civil and Industrial Sciences and Technologies, Abdelmalek Essaâdi University, Morocco \\ ${ }^{4}$ Mohammed V University, ENSIAS, Morocco \\ ${ }^{5}$ Abdelmalek Essaâdi University, Faculty of Sciences, Morocco
}

\section{Article Info}

Article history:

Received Jul 11, 2019

Revised Feb 27, 2020

Accepted Mar 8, 2020

\section{Keywords:}

Dual band-notched

Single rectangular split ring

resonator (SR-SRR)

Ultra-wideband (UWB)

WLAN

X-band

\begin{abstract}
A compact design of ultra-wideband (UWB) antenna with dual band-notched characteristics are investigated in this paper. The wider impedance bandwidth (from 2.73 to $11.34 \mathrm{GHz}$ ) is obtained by using two symmetrical slits in the radiating patch and another slit in the partial ground plane. The dual band-notch rejection at WLAN and X-band downlink satellite communication system are obtained by inserting a modified U-strip on the radiating patch at $5.5 \mathrm{GHz}$ and embedding a pair of single rectangular split ring resonators (SR-SRR) on both sides of the microstrip feed line at $7.5 \mathrm{GHz}$, respectively. The proposed antenna is simulated and tested using CST MWS high frequency simulator and exhibits the advantages of compact size, simple design and each notched frequency band can be controlled independently by using the geometrical parameters of the corresponding resonator. Therefore, the parametric study is carried out to understand the mutual coupling between the dual band-notched elements. To validate simulation results of our design, a prototype is fabricated and good agreement is achieved between measurement and simulation. Furthermore, a radiation patterns, satisfactory gain, current distribution and VSWR result at the notched frequencies make the proposed antenna a suitable candidate for practical UWB applications.
\end{abstract}

Copyright $@ 2020$ Institute of Advanced Engineering and Science. All rights reserved.

\section{Corresponding Author:}

Mohssine El Ouahabi,

Department of Civil and Industrial Sciences and Technologies,

National School of Applied Sciences,

Abdelmalek Essaâdi University,

Neighborhood Foum Oulik, Av Nasr N46, BP: 116 M'diq, Tetouan, Morocco.

Email: elouahabi87@gmail.com

\section{INTRODUCTION}

The Federal Communications Commission (FCC) has authorized the ultra-wide band (UWB) spectrum from $3.1 \mathrm{GHz}$ to $10.6 \mathrm{GHz}$ with signal bandwidth more than $500 \mathrm{MHz}$ for applications in commercial UWB communication systems [1]. UWB technology offers attractive features which include a high data transmission rate of more than $100 \mathrm{Mbps}$, low power and multi-path communication. Many techniques in the literature have been applied to design planar wideband antennas using microstrip $[2,3]$ or coplanar waveguide (CPW) slot antennas [4-6].

In recent years, a large number of interfering narrow-band communication systems operate in this broad bandwidth, like WiMAX (3.3-3.6 GHz), C-band systems (3.7-4.2 GHz), WLAN (5.15-5.825 GHz), and downlink of X-band satellite (7.25-7.75 GHz). So designing the UWB antennas without interfering with these narrow bands are required. Among the techniques that have been investigated to provide band-notched characteristic in order to meet this requirement, we find the following: embedding slots with different shapes in the radiating patch [7, 12], using quarter wavelength stubs attached in the ground plane [13], employing 
fractal and two via edge located (TVEL) electromagnetic band gap (EBG) structures near the feed line [14], using a parasitic rectangular strip [15], inserting split ring resonators (SRR) on the ground plane [16, 17] or using coplanar waveguide technology [18]. Other techniques have also been investigated by engraving two slots on radiating patch and a pair of rotated V-strip slot on the back side of the substrate [19], using slotted planar structure [20], using capacitor [21] however it needs to be reconfigurable. In [22], a slotted strip line structure is proposed.

In this work, a compact design of planar UWB antenna with dual-notch bands is investigated. The bandwidth and the adaptation of proposed UWB antenna are enhanced using two techniques: The first is loading the patch antenna by two symmetrical slits and the second one by introducing the slit in the partial ground plane. In order to create the dual band-notch rejection at WLAN and X-band downlink satellite, we introduce a modified U-strip on the radiating patch to have the $5.5 \mathrm{GHz}$ notch and by embedding a pair of rectangular SRRs on both sides of the microstrip feed line, we obtain the second notch at 7.5 GHz. Therefore, we simulate and discuss the parameters of the band notch antenna such as the VSWR, current distribution, radiation patterns and gain response. The size of the antenna is $24 \times 15 \times 1.6 \mathrm{~mm}$ and it's adapted for WLAN and X-band downlink satellite communication services.

\section{UWB ANTENNA GEOMETRY AND DESIGN CONSIDERATION}

\subsection{UWB antenna geometry}

Figure 1 shows the procedure to designing UWB antenna, which is printed on Fr-4 substrate with a dimension of $24 * 15 \mathrm{~mm}^{2}$, relative dielectric constant $\mathrm{\varepsilon r}=4.4$, thickness of $1.6 \mathrm{~mm}$ and loss tangent of 0.02 . Figure 2 shows the VSWR simulation for each step of presented antenna Figure 1 (from (Ant. 1) to (Ant. 3)) that allows us to obtain an UWB antenna as a result Figure 1 (Ant. 3).

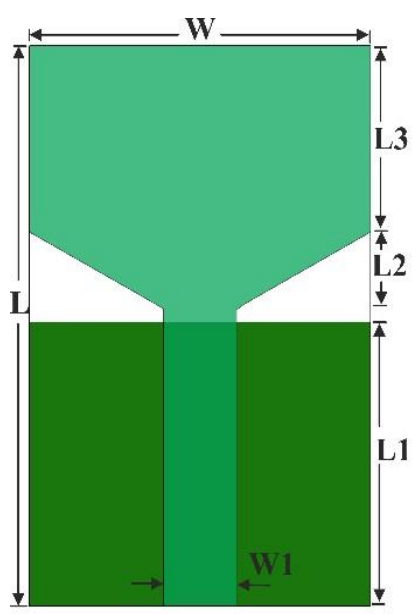

Ant.1

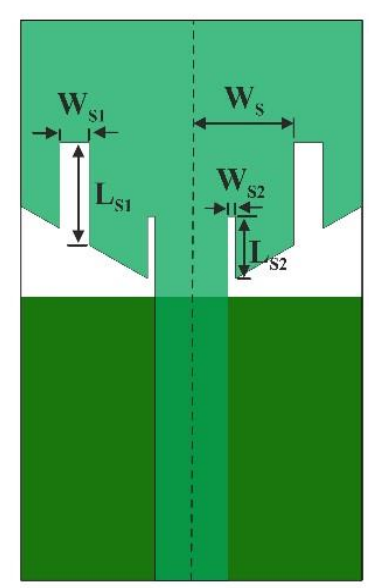

Ant.2

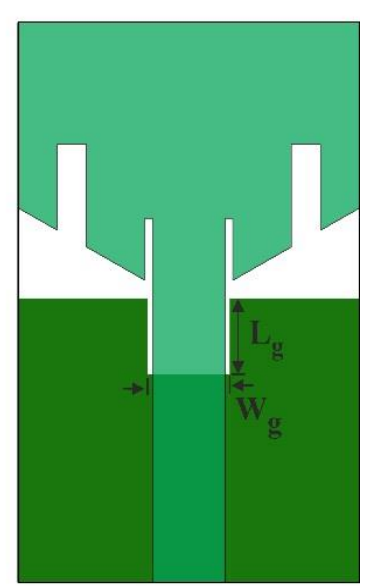

Ant.3

Figure 1. Steps of improvement of the proposed UWB antenna: (Ant. 1) initial square antenna with symmetrical bevel, (Ant. 2) antenna with two symmetrical slits in the radiator and (Ant. 3) antenna with rectangular slit in the ground plane

In the first step, and based on theory and recent studies, the initial design is the square antenna with symmetrical bevel, as shown in Figure1(Ant. 1). In the second step, The design was developed and optimised by considering different aspects such as the improvement of impedance matching and bandwidth. The radiating element is loading by two symmetrical slits to obtain better impedance matching and by introducing a slit on the partial ground plane, broadband impedance bandwidth can be achieved, as shown in Figure 1 (Ant. 2) and (Ant. 3) respectively.

From the following Figure 2, we can see that the effect of the slits introduced in the patch and on the back side the substarte of our antenna was the widening of the bandwidth in a progressive manner. Also, we can conclude that the result of VSWR of the last antenna (Ant.3) is satisfactory because it obeys the law of an UWB antenna and whose VSWR is inferior to 2. The optimum dimensions of the UWB antenna design are as follows : $\mathrm{L}=24 \mathrm{~mm}, \mathrm{~L} 1=13 \mathrm{~mm}, \mathrm{~L} 2=2.4, \mathrm{~L} 3=8 \mathrm{~mm}, \mathrm{LS} 1=2.85 \mathrm{~mm}, \mathrm{LS} 2=1.7 \mathrm{~mm}, \mathrm{Lg}=3.4$, $\mathrm{W}=15 \mathrm{~mm}, \mathrm{~W} 1=3.14, \mathrm{WS}=3.2 \mathrm{~mm}, \mathrm{WS} 1=0.7 \mathrm{~mm}, \mathrm{WS} 2=0.2 \mathrm{~mm}$ and $\mathrm{Wg}=4 \mathrm{~mm}$. 


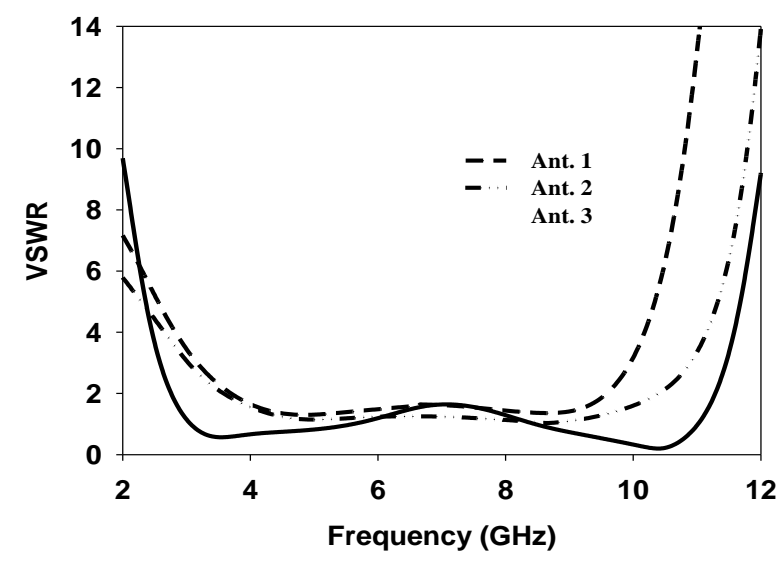

Figure 2. Simulated VSWR for different UWB antenna structures

\subsection{UWB antenna with dual band notch geometry}

After the success in creating a compact printed monopole UWB antenna (without a band notch). Figure 3 illustrates two steps followed in producing dual-notched band characteristic on UWB radiator. The first one consists on creating a slit on the radiating patch and after that, adding a modified U-strip resonator inside the previous slit that leads to provide the first notch at $6 \mathrm{GHz}$. However, the second one consists on embedding a pair of SR-SRR on each side of the feed line which leads to provide another notch at $8.2 \mathrm{GHz}$. The detailed values of the two resonators are displayed in Table 1.

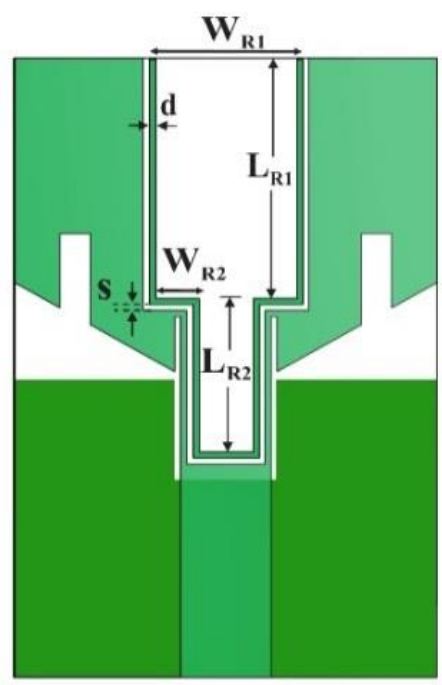

(a)

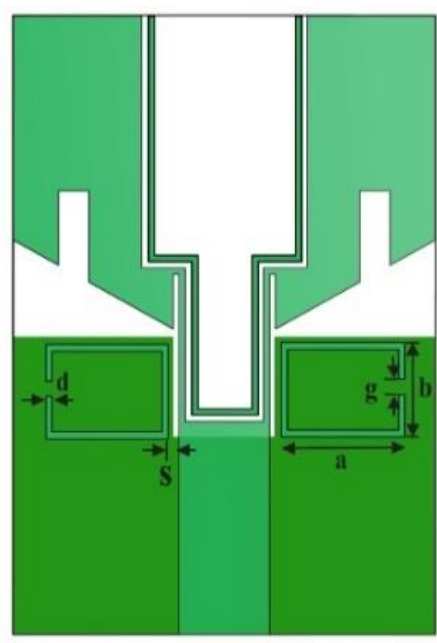

(b)

Figure 3. (a) Antenna with modified U-strip, (b) Antenna with modified U-strip and pair of SR-SRR

Table 1. dual band-notched antenna dimensions

\begin{tabular}{cc}
\hline Parameters & Value $(\mathrm{mm})$ \\
\hline $\mathrm{a}$ & 4 \\
$\mathrm{~b}$ & 2.7 \\
$\mathrm{~g}$ & 0.8 \\
$\mathrm{~d}$ & 0.2 \\
$\mathrm{~s}$ & 0.2 \\
$\mathrm{~W}_{\mathrm{R} 1}$ & 5.1 \\
$\mathrm{~W}_{\mathrm{R} 2}$ & 1.45 \\
$\mathrm{~L}_{\mathrm{R} 1}$ & 7.6 \\
$\mathrm{~L}_{\mathrm{R} 2}$ & 4.3 \\
\hline
\end{tabular}




\section{SIMULATION RESULTS AND DISCUSSION}

\subsection{VSWR}

The simulated VSWR of the proposed antenna is shown in Figure 4, where VSWR of UWB antenna (without any resonator) is compared to VSWRs of the antenna having the single and dual band-reject performance, respectively. The designed UWB antenna has broadband performance from 2.78 to $11.34 \mathrm{GHz}$ with VSWR $<2$, which covers all of the UWB frequency band. Furthermore, it can be clearly seen that each resonator creates a corresponding notched band with VSWR $>2$ at these notches. These results mean that there are no power transmissions at notches frequencies. However, to better explain the correlation between the band-notched elements and tuned each rejected band to the desired value, a parametric study is carried out by varying one parameter at a time and fixing the others.

\subsubsection{The WLAN rejected band}

The first notch can be generated by adding a modified U-strip resonator inside a slit in the radiator. The length of this resonator is calculated as $L_{n o t c h 1}=2 L_{R 1}+2 L_{R 2}+W_{R 1}$. The following formula [23] can explain the dependence between the overall length $\left(\mathrm{L}_{\text {notch } 1}\right)$ of the modified U-strip resonator and the first

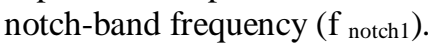

$$
f_{\text {notch } 1}=\frac{C}{L_{n o t c h 1} \sqrt{\frac{\varepsilon_{r}+1}{2}}}
$$

where $\mathrm{C}$ is velocity of light through free space and $\mathrm{cr}$ is dielectric constant.

Figure 5 shows the simulated VSWR parameters for different values of " $\mathrm{L}_{\mathrm{R} 2}$ ". It can be seen that the VSWR at the notched bands is dependent on " $\mathrm{L}_{\mathrm{R} 2}$ " values. The notched bands shift toward the lower frequency band when " $L_{R 2}$ " increases. The optimum value of " $L_{R 2}$ " to cover the desired notched band centred at $5.5 \mathrm{GHz}$ (WLAN) band is $5.7 \mathrm{~mm}$.

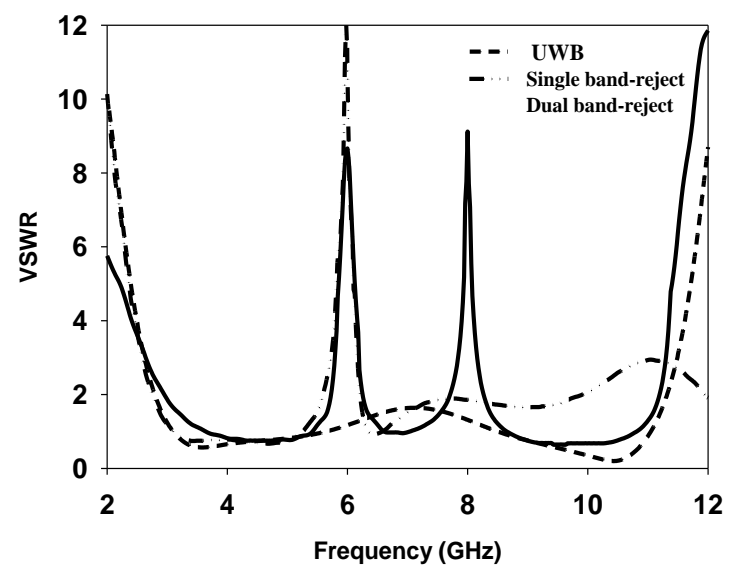

Figure 4. Simulated VSWR for different structures

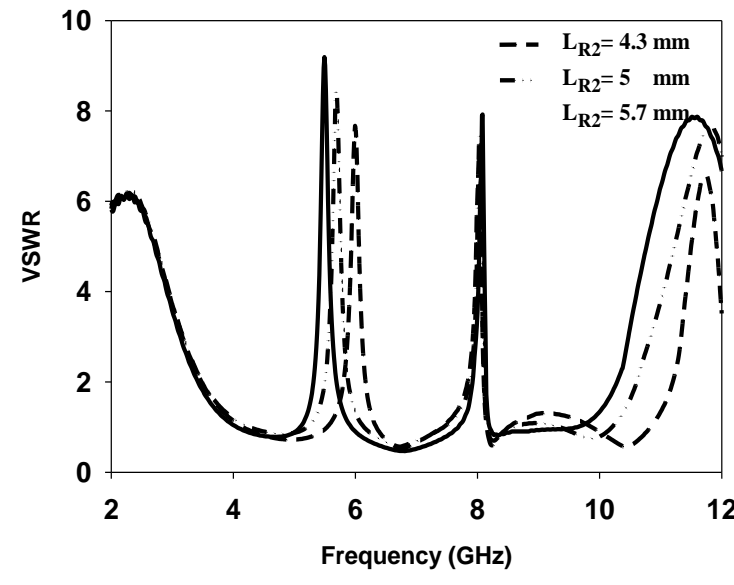

Figure 5. VSWR parameters for different modified U-strip length " $\mathrm{L}_{\mathrm{R} 2}$ "

\subsubsection{The $X$-band rejected band}

Also the second frequency notch is generated by embedding the SR-SRR on side the microstrip feed line. The length of this resonator is calculated as $L_{n o t c h}=2 a+2 b-g$. By using the formula (2), the relationship

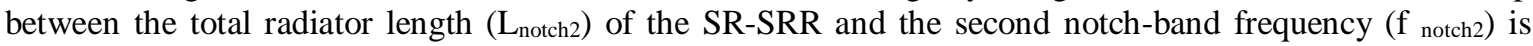
calculated using the following formula [24]:

$$
f_{\text {notch } 2}=\frac{C}{2 L_{\text {notch } 2} \sqrt{\frac{\varepsilon_{r}+1}{2}}}
$$


Figure 6 depicts the influence of "g" the rectangular SRR- Split width to the second-band reject. It indicates that when the dimension of " $\mathrm{g}$ " is varied from 0.8 to 0.4 , only the second notch band shifts, so the optimum value of " $\mathrm{g}$ " to obtain a notch band at $7.5 \mathrm{GHz}$ is $0.4 \mathrm{~mm}$. According to the parametric study above, it is observed that the first frequency notch (WLAN) is achieved at $5.5 \mathrm{GHz}$ and the second (X-band) is achieved at $7.5 \mathrm{GHz}$. It also confirmed that the geometrical parameters of each resonator are used to adjust the position of the corresponding unwanted band. Moreover, the optimal result of VSWR of the suggested antenna is illustrated in Figure 7.

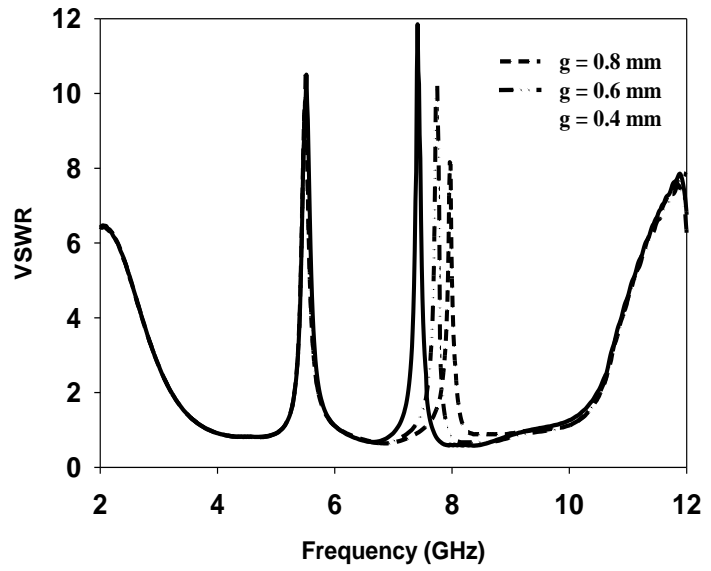

Figure 6. VSWR parameters for different rectangular SRR -split width "g"

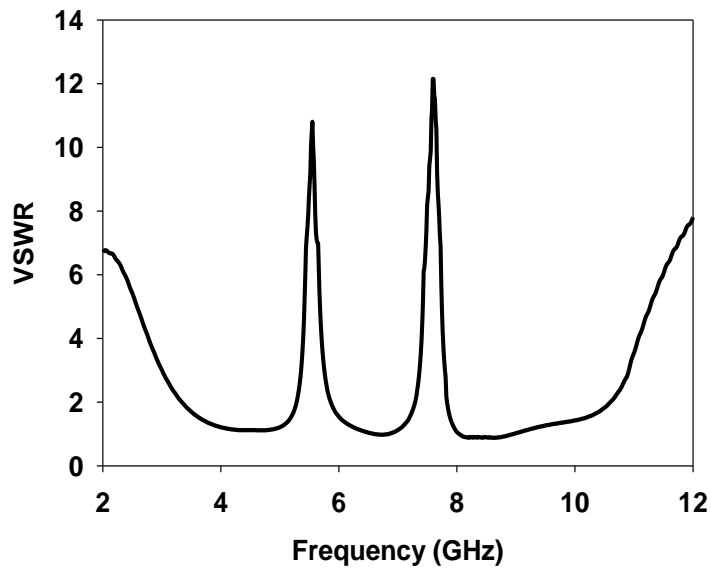

Figure 7. Optimal result of VSWR of a dual-band notch antenna

\subsection{Current distribution and gain}

To further understand the phenomenon behind dual notch performance, the surface current is also investigated at frequencies of 5.5 and $7.5 \mathrm{GHz}$. As shown in Figure 8(a), at $5.5 \mathrm{GHz}$ notched frequency, the stronger current is mainly focused over the modified U-strip resonator inside the radiation patch. Figure 8(b) shows the current distribution at $7.5 \mathrm{GHz}$, which corresponds to the upper notched frequency. The current distribution is more concentrated over a pair of SR-SRR and very week on radiating patch and on modified U-strip. Therefore, at the notched-bands, the energy cannot be radiated and it is stored around the resonators. Figure 9 shows the simulated antenna gain versus frequency over the whole impedance bandwidth. The gain at the notched frequency bands is significantly reduced. It clearly indicates that these resonators can perfectly prevent the propagation of the signal close to its resonant frequencies.

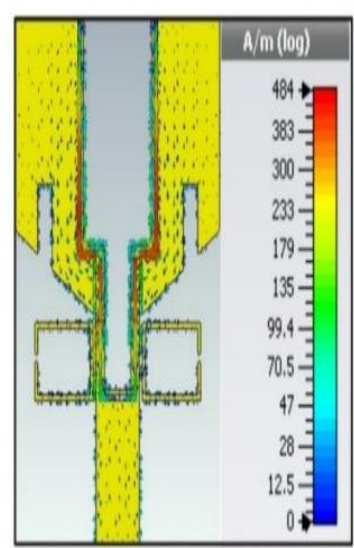

(a)

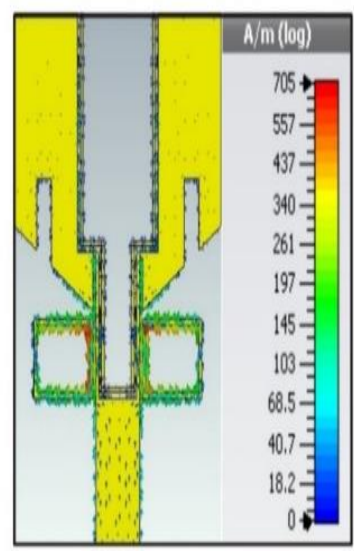

(b)

Figure 8. Simulated current distributions at different frequncies: (a) $5.5 \mathrm{GHz}$. (b) $7.5 \mathrm{GHz}$

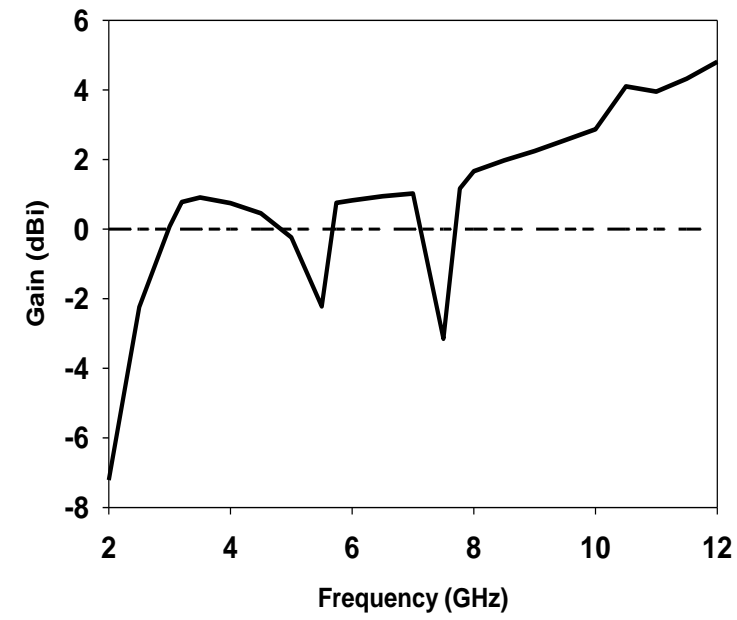

Figure 9. Simulated gain of the optimized UWB antenna with dual notches 


\section{FABRICATION AND MEASUREMENT}

In order to validate the design of dual band-notch UWB antenna, a prototype has been successfully fabricated using LPKF ProtoMat E33 and tested using A Rohde and Schwarz ZVB 20 vector network analyzer. Figures 10 (a) and (b) show a photograph of fabricated antenna, The simulated and measured results of our antenna are plotted in Figure 11 and listed in Table 2.

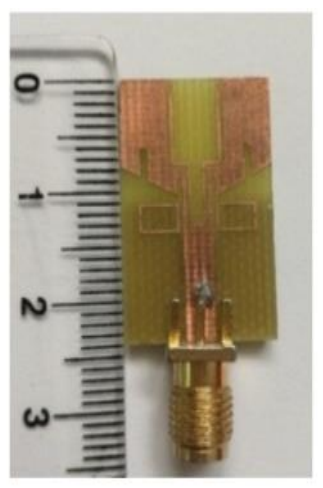

(a)

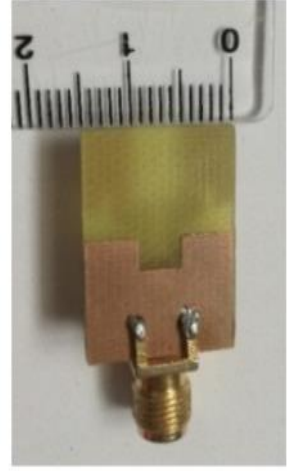

(b)

Figure 10. Prototype of dual band-notch antenna (a) front view, (b) bottom view

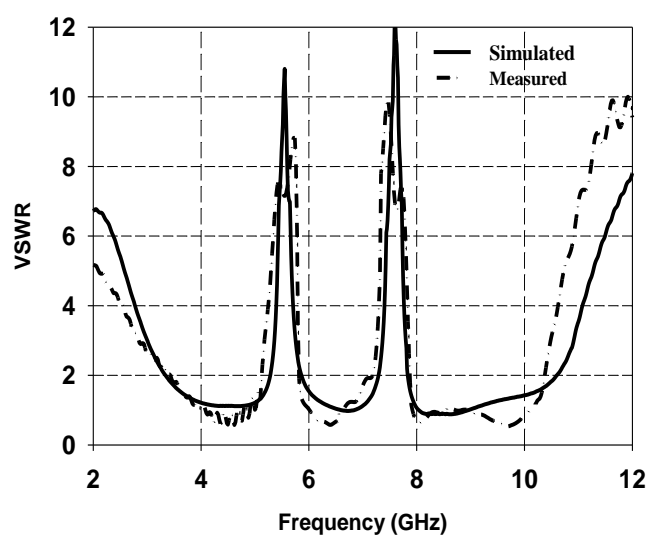

Figure 11. Simulated and measured VSWR

Table 2. Comparative table between the antennas discussed

\begin{tabular}{ccc}
\hline Parameters & Simulated Results & Fabricated Results \\
\hline Bandwidth & 3.28 to $10.65 \mathrm{GHz}$ & 3.38 to $10.5 \mathrm{GHz}$ \\
First Notch (WLAN) & 5.25 to $5.85 \mathrm{GHz}$ & 5.13 to $5.82 \mathrm{GHz}$ \\
Second Notch (X-band) & 7.26 to $7.81 \mathrm{GHz}$ & 7.18 to $7.86 \mathrm{GHz}$ \\
\hline
\end{tabular}

The fabricated antenna has a large bandwidth from $3.38 \mathrm{GHz}$ to10.5 GHz for VSWR<2 with dual notched bands in the range of WLAN and X-band. A slight discrepancy exists among the rejected bands. Some of these slight discrepancies can be attributed to connector mismatches and manufacturing tolerances. The radiation patterns of the designed antenna at the frequencies $4 \mathrm{GHz}, 6.5 \mathrm{GHz}$ and $9 \mathrm{GHz}$ in the $\mathrm{E}$ and $\mathrm{H}$ planes are simulated, measured and compared, as shown in Figure 12. A nearly omnidirectional radiation characteristics are observed in the $\mathrm{H}$-plane. While in E-plane, the radiation pattern is similar to that of the dipoles. Table 3 summarized the comparison of proposed design and published works in terms of frequency notches, peak VSWR at center notched frequency, paek gain and full size. As observed, the proposed design is compact in size as compared to all the references taken.
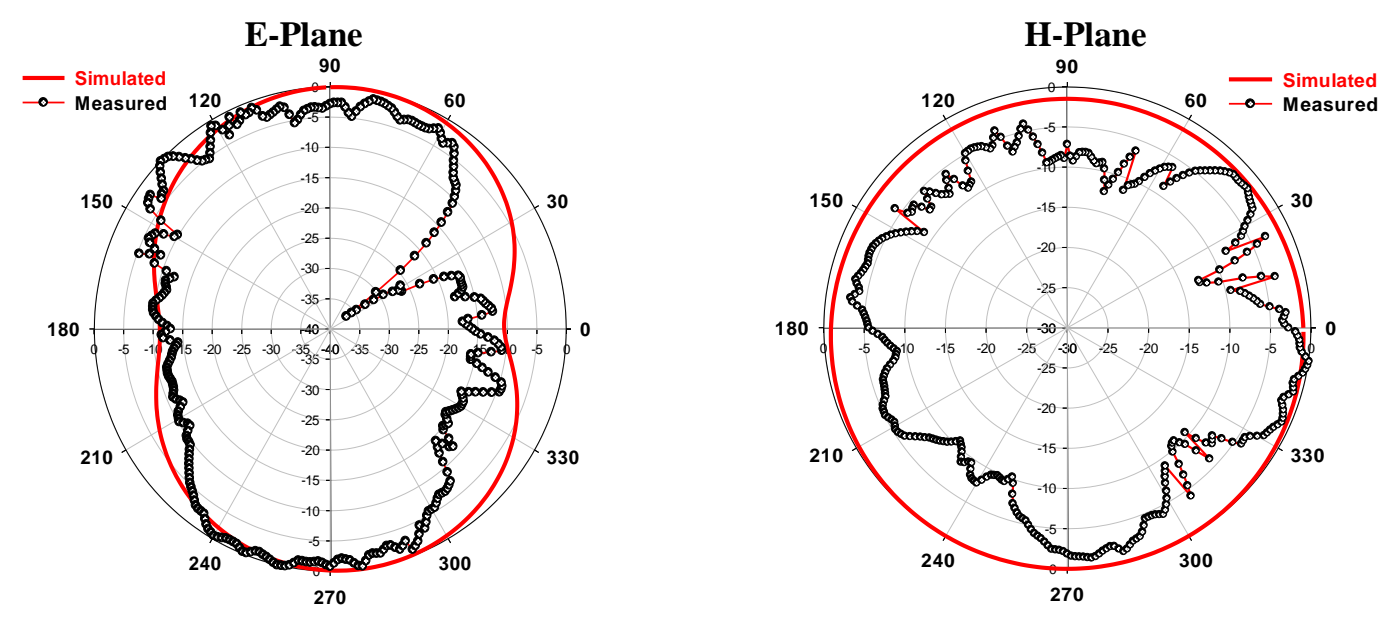

(a)

Figure 12. Simulated and measured radiation patterns at (a) $4 \mathrm{GHz}$ 

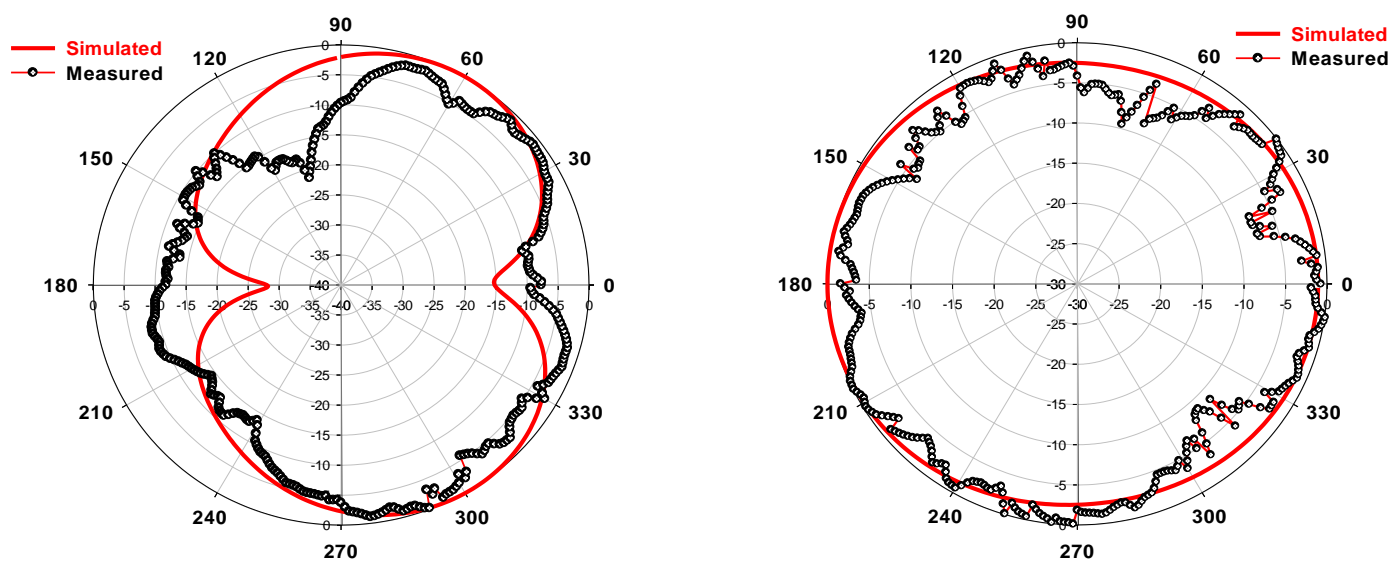

(b)
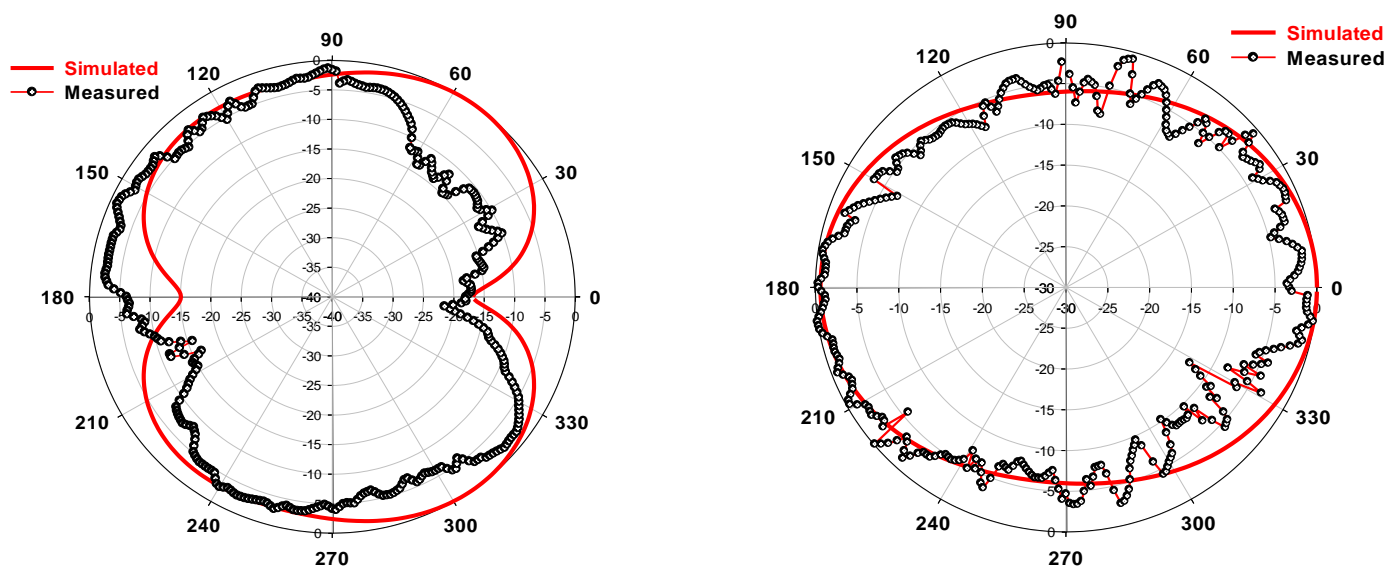

(c)

Figure 12. Simulated and measured radiation patterns at (b) $6.5 \mathrm{GHz}$ and (c) $9 \mathrm{GHz}$ (continue)

Table 3 summarized the comparison of proposed design and published works in terms of frequency notches, peak VSWR at center notched frequency, paek gain and full size. As observed, the proposed design is compact in size as compared to all the references taken.

Table 3. Comparative table between the proposed and existing antennas

\begin{tabular}{cccccccc}
\hline Ref. & $\begin{array}{c}\text { Size } \\
(\mathrm{mm} 3)\end{array}$ & $\begin{array}{c}\text { Freq. } \\
(\mathrm{GHz})\end{array}$ & $\begin{array}{c}\text { VSWR First } \\
\text { Notch }\end{array}$ & $\begin{array}{c}\text { Peak Gain } \\
(\mathrm{dBi})\end{array}$ & $\begin{array}{c}\text { Freq. } \\
(\mathrm{GHz})\end{array}$ & $\begin{array}{c}\text { VSWR Second } \\
\text { Notch }\end{array}$ & $\begin{array}{c}\text { Peak Gain } \\
(\mathrm{dBi})\end{array}$ \\
\hline$[24]$ & $21.8 \times 24.1 \times 1.6$ & 4 & 4 & -12 & 7.7 & 7 \\
{$[25]$} & $26 \times 30 \times 1.6$ & 5.5 & 2.8 & 0 & 7.7 & -7 \\
{$[26]$} & $40 \times 40 \times 0.762$ & 5.78 & 14.8 & -14.5 & 8.2 & -17 \\
{$[27]$} & $33 \times 34 \times 1.575$ & 4.3 & 4 & -4 & 7.7 & -16.5 \\
Proposed & $24 \times 15 \times 1.6$ & 5.5 & 10.4 & -2 & 7.5 & 6 \\
\hline
\end{tabular}

\section{CONCLUSION}

In this paper, A compact planar UWB antenna with dual band-notched characteristics has been presented. The desired stop bands with centre frequencies at $5.5 \mathrm{GHz}$ and $7.5 \mathrm{GHz}$ are obtained by inserting a modified U-strip on the radiating patch and incorporating a SR-SRR on each side of the microstrip feed line, respectively. Moreover, the central frequency of the notches could be easily adjusted by altering the geometrical parameters of corresponding resonator. VSWR, current distribution, gain and radiation pattern are taken into account to analyse the performance of the proposed antenna. In addition, The H-plane shows nearly omnidirectional radiation patterns over the operating frequency range. From the above results, it can be concluded that the performance of proposed antenna is adequate for UWB wireless communications applications except WLAN and downlink signals of the X-band satellite communication services. 


\section{REFERENCES}

[1] First Report and order, "Revision of part 15 of the commission's rule regarding ultra-wideband transmission system," Federal Communications Commission, pp. 02-48, 2002.

[2] R. Azim, M. T. Islam, J. S. Mandeep, and A. T. Mobashsher, "A planar circular ring ultra-wideband antenna with dual band-notched characteristics," Journal of Electromagnetic Waves and Applications., vol. 26, no. 14-15, pp. 2022-20321, 2012.

[3] P. Li, J. Liang, and X. Chen, "Study of Printed Elliptical / Circular Slot Antennas for Ultrawideband Applications," IEEE Transactions on antennas and Propagation, vol. 54, no. 6, pp. 1670-1675, 2006.

[4] X. Liao, H. Yang, N. Han, and Y. Li, "Aperture UWB antenna with triple band-notched characteristics," Electronics letters, vol. 47, no. 2, pp. 77-79, 2011.

[5] H. Chen, Y. Ding, and D. S. Cai, "A CPW-Fed Uwb Antenna With WiMAX/WLAN Band-Notched Characteristics," Progress In Electromagnetics Research Letters, vol. 25, pp. 163-173, 2011.

[6] W.-T. Li and Y.-Q. Hei, "Design of Ultrawideband Antenna with Multiple Band-Notched Characteristics," Journal of Electromagnetic Waves and Application,, vol. 26, no. 7, pp. 942-951, 2012.

[7] A. Majeed and K. Sayidmarie, "UWB elliptical patch monopole antenna with dual-band notched characteristics," International Journal of Electrical and Computer Engineering(IJECE), vol. 9, no. 5, pp. 3591-3598, 2019.

[8] M. O. Al-dwairi, "A planar UWB semicircular-shaped monopole antenna with quadruple band notch for WiMAX, ARN , WLAN , and X-Band," International Journal of Electrical and Computer Engineering(IJECE), vol. 10, no. 1, pp. 908-918, 2020.

[9] S. Maiti, S. Das, and N. Pani, "Compact Planar G-shape UWB Antenna with Notch characteristics for Satellite Communication," IEEE Fifth International Conference on Computing, Communications and Networking Technologies (ICCCNT), pp. 11-13, 2014.

[10] R. Sanyal, P. P. Sarkar, and S. K. Chowdhury, "Miniaturized band notched UWB antenna with improved fidelity factor and pattern stability," Radioengineering, vol. 27, no. 1, pp. 39-46, 2018.

[11] A. D. Farhood, M. K. Naji, S. H. Rhaif, and A. H. Ali, "Design and analysis of dual band integrated hexagonal shaped microstrip UWB antenna," Indonesian Journal of Electrical Engineering and Computer Science, vol. 15, no. 1, pp. 294-299, 2019.

[12] L. Rekha, D. Shankar, and P. Narayan, "Compact Integrated Bluetooth UWB Antenna with Quadruple Bandnotched Characteristics," International Journal of Electrical and Computer Engineering (IJECE), vol. 5, no. 6, pp. 1433-1440, 2015.

[13] W. Thomas and A. A. A. Jone, "Miniaturization of UWB Antenna for Satellite Applications with Dual Notch Band," IEEE International Conference on Engineering and Technology (ICETECH), pp. 6-8, 2015.

[14] M. A. Trimukhe and B. G. Hogade, "Compact Ultra-Wideband Antenna with Triple Band Notch Characteristics Using EBG Structures,” Progress In Electromagnetics Research,, vol. 93, no. April, pp. 65-77, 2019.

[15] N. Malekpour, M. A. Honarvar, A. Dadgarpur, B. S. Virdee, and T. A. Denidni, "Compact uwb mimo antenna with band-notched characteristic," Microwave and Optical Technology Letters, vol. 59, no. 5, pp. 1037-1041, 2017.

[16] L.-C. Tsai and W.-J. Chen, "A UWB Antenna With Band- Notched Filters Using Slot-Type Split Ring Resonators," Microwave and Optical Technology Letters., vol. 58, no. 11, pp. 2595-2598, 2016.

[17] P. M. Paul, K. Kandasamy, and M. S. Sharawi, "A tri-band slot antenna loaded with split ring resonators," Microwave and Optical Technology Letters., vol. 59, no. 10, pp. 2638-2643, 2017.

[18] K. Fertas, H. Kimouche, M. Challal, H. Aksas, R. Aksas, and A. Azrar, "Design and Optimization of a CPW-Fed Tri-band Patch Antenna using Genetic Algorithms," Applied Computational Electromagnetics Society Journal, vol. 30, no. 7, pp. 754-759, 2015.

[19] M. Rostamzadeh, S. Mohamadi, J. Nourinia, C. Ghobadi, and M. Ojaroudi, "Square Monopole Antenna for UWB Applications With Novel Rod-Shaped Parasitic Structures and Novel V-Shaped Slots in the Ground Plane," IEEE Antennas and Wireless Propagation Letters, vol. 11, pp. 446-449, 2012.

[20] A. Ibrahim, W. Ali, And J. Machac, "UWB Monopole Antenna with Band Notched Characteristics Mitigating Interference with WiMAX," Radioengineering, vol. 26, no. 2, pp. 438-443, 2017.

[21] C. Hua, Y. Lu, and T. Liu, "UWB Heart-Shaped Planar Monopole Antenna with a Reconfigurable Notched Band," Progress In Electromagnetics Research Letters. Res. Lett., vol. 65, pp. 123-130, 2017.

[22] A. Verma and M. Singh Parihar, "Multifunctional Antenna with Reconfigurable Ultra-Wide Band Characteristics," Radioengineering, vol. 26, no. 3, pp. 647-654, 2017.

[23] R. Azim and M. T. Islam, "Compact Planar Uwb Antenna With Band Notch Characteristics For WLAN And DSRC," Progress In Electromagnetics Research, vol. 133, pp. 391-406, 2013.

[24] S. K. Vijay et al., "UWB Antenna with Dual Band Notch Characteristics," International Journal of Engineering and Advanced Technology, vol. 8, no. 5, 2019.

[25] A. Yadav, D. Sethi, and R. K. Khanna, "Slot Loaded UWB Antenna: Dual Band Notched Characteristics," International Journal of Electronics and Communications, vol. 70, no. 3, pp. 331-335, 2016.

[26] H. A. Atallah, A. B. Abdel-rahman, K. Yoshitomi, and R. K. Pokharel, "Design of Dual Band-Notched CPW-Fed UWB Planar Monopole Antenna Using Microstrip Resonators," Progress In Electromagnetics Research Letters, vol. 59, pp. 51-56, 2016.

[27] A. Iqbal, O. A. Saraereh, and S. K. Jaiswal, "Maple Leaf Shaped UWB Monopole Antenna with Dual Band Notch Functionality," Progress In Electromagnetics Research C, vol. 71, pp. 169-175, 2017. 


\section{BIOGRAPHIES OF AUTHORS}

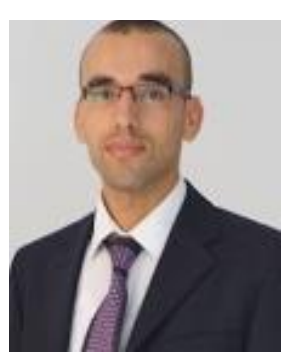

Mohssine El Ouahabi was born in 1987 M'diq, Morocco. He received a Master degree in Telecommunication systems engineering from Abdelmalek Essaâdi University, Tetuan, Morocco, in 2013. He is currently working toward on a PhD degree in microwave circuits using the metamaterial structure at the same University.

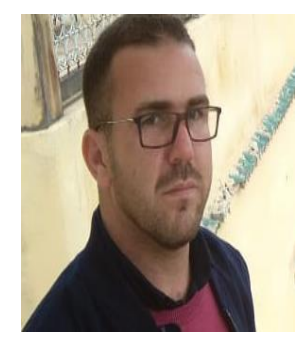

Aziz Dkiouak was born in December 1985, in Tayjoute town, $30 \mathrm{Km}$ from Chefchaouen, Morroco. He received the Master's degree in Electronics and Telecommunications at the Faculty of Sciences, Abdelmalek Essaâdi University, Tetouan, Morocco in 2010. He is currently working on a Ph.D. degree and His research focuses on the design and realization of MIMO antennas with high isolation and a compact size for wireless applications.

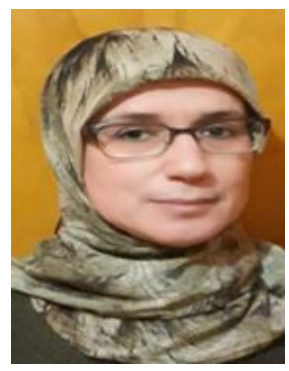

Alia Zakriti received PhD degree in Electrical Engineering in 2001 from University Abdelmalek Essaâdi (UAE), Morocco. During 2004-2010, she was professor at Caddi Ayad University, Morocco. Since 2010, she joined the National School of Applied Sciences, UAE, as a Professor of Electrical Engineering. She directed a Research Unit "Advanced Science and Technology" during several years and she was also a head of department of Civil and Industrial Sciences and Technologies. Her research interests focus mainly on printed microwave circuits and embedded systems.

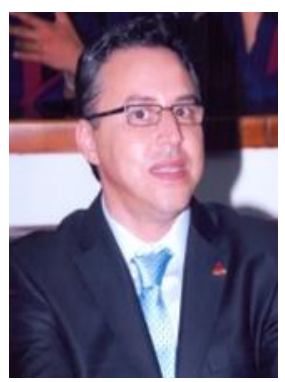

Mohamed Essaaidi. (SM'00) is a Professor of electrical and computer engineering at Abdelmalek Essaadi University, Morocco. His research interests focus mainly on RF and microwave circuits and antennas for wireless communications and medical systems and Wireless Sensor Networks (WSN). He is the author and coauthor of more than 95 papers. Prof. Essaaidi is a member of the IEEE Microwave Theory and Techniques Society, IEEE Antennas and Propagation Society, IEEE Communications Society, IEEE Computer Society and European Microwave Association. He is the Founder and the General Chair of Mediterranean Microwave Symposium (MMS) since 2000.

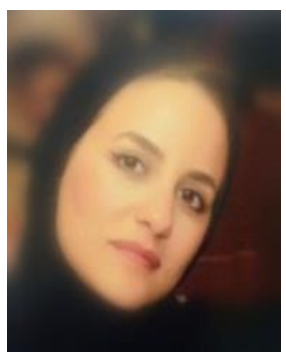

Hanae Elftouh was born in 1987, Tetouan, Morocco. She received a Master degree in Telecommunication systems engineering from Abdelmalek Essaâdi University, Tetuan, Morocco, in 2010. She received PHD degree in microwave circuits in 2016 at the same university. Her research interests on miniaturization of printed microwave circuits (antennas and filters). She has authored and co-authored several papers in different international indexed journals and conferences in the field of microwave communications Technology. 